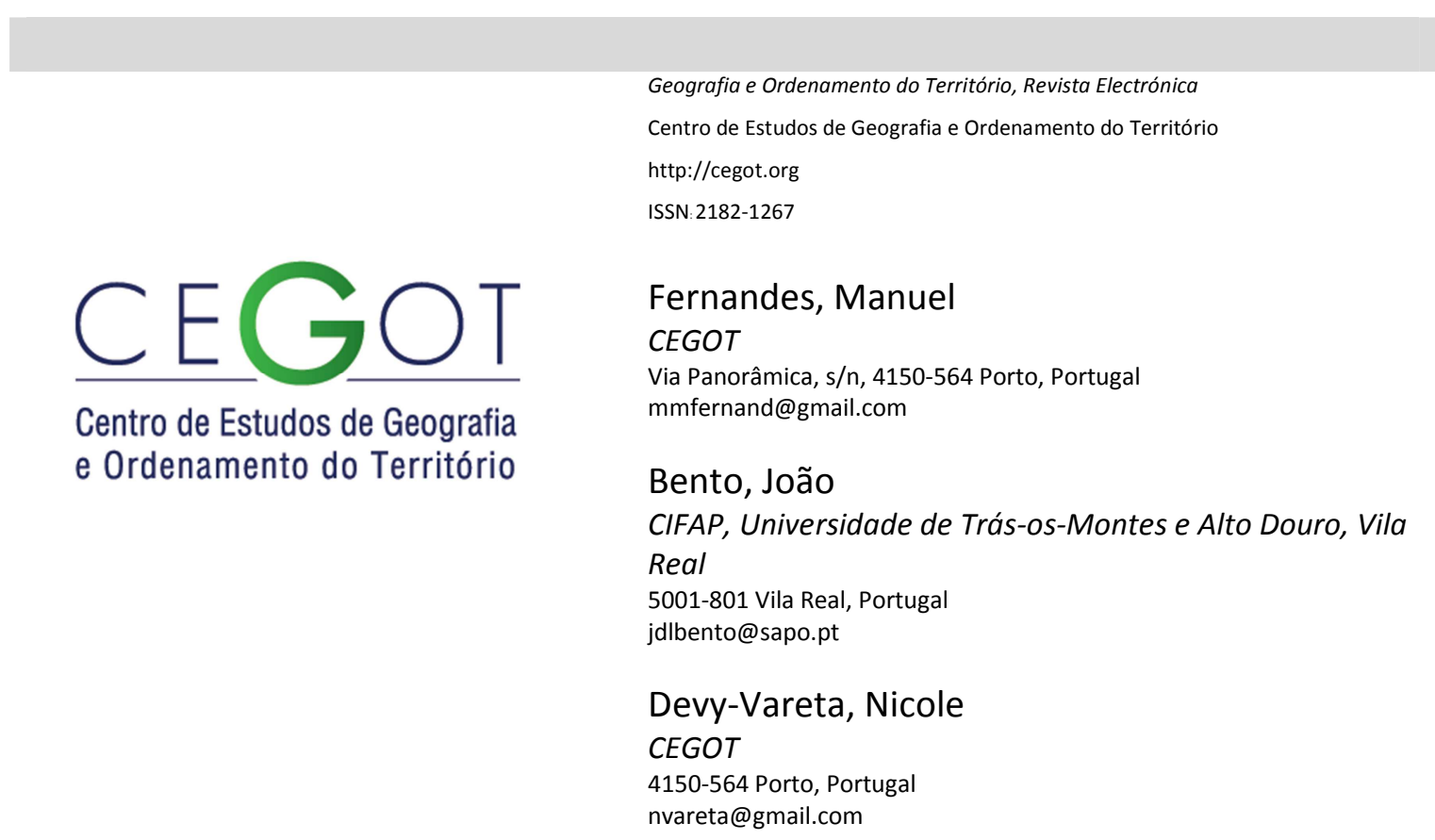

\title{
Aspetos biogeográficos e paleoambientais de uma população finícola de Pinus sylvestris L. na serra do Gerês (NW Portugal)
}

Referência: Fernandes, Manuel et al. (2015). Aspetos biogeográficos e paleoambientais de uma população finícola de Pinus sylvestris L. na serra do Gerês (NW Portugal). (GOT), n.o 7 (junho). Centro de Estudos de Geografia e Ordenamento do Território, p. 159-181, dx.doi.org/10.17127/got/2015.7.007

\section{Resumo}

A descoberta de uma população de Pinus sylvestris L. na serra do Gerês, nos finais do séc. XIX, abriu desde logo um debate sobre o carácter autóctone desta espécie em Portugal. Neste artigo apresentam-se dados paleoambientais sobre a presença da espécie na Peninsula Ibérica e em Portugal, desde o último ciclo glaciar. Exploram-se documentos que, a partir do séc. XVIII, referem $P$. sylvestris na vegetação do país e, particularmente, na serra do Gerês. Discutem-se as hipóteses levantadas sobre a espontaneidade do núcleo geresiano e sobre as tentativas de introdução da espécie em várias áreas do país, antes do seu uso em maior escala na florestação das serras no séc. XX. Por último, admite-se o carácter relicto e autóctone de $P$. sylvestris na serra do Gerês e salienta-se a importância da conservação deste património biogenético.

Palavras-Chave: Pinus sylvestris L., Gerês, Biogeografia, Paleobotânica, espécies autóctones, florestação

\section{Abstract}

The discovery of a population of Pinus sylvestris L. in the Gerês mountains in the late $19^{\text {th }}$ century opened a debate about its native status in Portugal. This paper reviews palaeoenvironmental data on the occurrence of the species in the Iberian Peninsula and in Portugal since the last glacial period. Written sources since the $18^{\text {th }}$ century where $P$. 
sylvestris is mentioned from the country vegetation and the Gerês mountains are also examined. The hypothesis of the native status of the Gerês population is discussed, along with the attempts to introduce this pine species in different locations of the country, prior to the afforestation of mountain areas in the $20^{\text {th }}$ century. The native status of the surviving populations in Gerês is admitted and the importance of its conservation as a biogenetic resource is stressed.

Keywords: Pinus sylvestris L., Gerês, Biogeography, Paleobotany, native species, afforestation

\section{Introdução}

As populações de Pinus sylvestris L. consideradas autóctones na Península Ibérica apresentam uma posição biogeográfica singular, dado que se localizam no extremo ocidental da área de distribuição desta espécie, sendo constituídas por núcleos fragmentados e isolados em áreas montanhosas, desde os Pirenéus até à Cordilheira Bética (Critchfield \& Little 1966; Martínez García \& Montero 2000). Estas populações diferenciam-se morfoecológica e geneticamente das restantes populações europeias (Prus-Głowacki et al. 2003), estando descritas na Península Ibérica cinco variedades nativas de $P$. sylvestris (Franco 1986). No entanto, os critérios para distinguir os núcleos autóctones desta espécie dos povoamentos silvícolas nem sempre são claros (Martínez García 1999).

A atual distribuição dos núcleos de $P$. sylvestris com origem autóctone no território ibérico tem sido relacionada com as alterações paleoclimáticas verificadas desde o final do Terciário, hipótese que remonta a Teixeira (1944) e a Gaussen (1950), que admitem a expansão de $P$. sylvestris e de outras espécies de "clima frio" no final do Pliocénico. Trabalhos posteriores têm revisto e aprofundado a história paleoambiental de $P$. sylvestris na Península Ibérica, conjugando as modificações paleoclimáticas com a localização de áreas de refúgio, a existência de barreiras biogeográficas e a influência da atividade humana (Benito Garzón et al. 2008; Figueiral \& Carcaillet 2005; García-Amorena et al. 2007; GómezOrellana et al. 2012).

É neste contexto biogeográfico que se torna relevante a ocorrência de uma população finícola de $P$. sylvestris no NW de Portugal, referenciada no final do séc. XIX na serra do Gerês (Almeida 1894). O caráter autóctone desta população, admitido por botânicos como Pereira Coutinho, Júlio Henriques ou Jules Daveau (Coutinho 1913; Daveau 1894; Henriques 
1896), serviu de motivo para efetuar uma multiplicação ex situ dos exemplares remanescentes, com o objetivo de instalar futuros povoamentos de $P$. sylvestris em áreas montanhosas elevadas; contudo, persistiram dúvidas sobre o estatuto nativo da população geresiana, devido à existência de tentativas anteriores de florestação com esta espécie (Sousa 1918). Apesar de algumas iniciativas fortuitas para esclarecer tais dúvidas (e. g., Tavares 1948), só em 2008/2009 se procedeu a novas determinações biométricas e dendrocronológicas num dos núcleos remanescentes, com suposta origem autóctone, tendo sido registados exemplares de $P$. sylvestris com mais de dois séculos de idade (Almeida \& Fernandes 2009). Esta averiguação contribuiu para o projeto SILVESTRE - Pinheiro-silvestre em Portugal: o "extremo sudoeste" ou apenas "o fim"? (Projeto PTDC/AGRCFL/110988/2009), submetido à Fundação para a Ciência e a Tecnologia pela Universidade de Trás-os-Montes e Alto Douro, com o objetivo de estudar a provável origem autóctone da população de $P$. sylvestris da serra do Gerês, no contexto dos restantes povoamentos desta espécie em Portugal (Lima-Brito et al. 2014).

O presente artigo, articulado com este projeto, analisa os principais estudos biogeográficos e paleoambientais sobre $P$. sylvestris, no contexto ibérico e geresiano, e procura relacionar a história recente dos núcleos de $P$. sylvestris da serra do Gerês com aspetos institucionais das políticas florestais e de conservação da natureza. A recensão efetuada mostra que os avanços no conhecimento desta problemática resultam do cruzamento de várias disciplinas científicas, e de diferentes sensibilidades, desde a arqueologia e a paleobotânica às ciências florestais e à geografia, entre outros campos do saber científico, pelo que o aprofundamento das linhas de pesquisa examinadas requer a continuidade de uma articulação pluridisciplinar.

\section{Metodologia}

A metodologia utilizada baseou-se na recensão de estudos paleobotânicos sobre a ocorrência de Pinus sylvestris na Península Ibérica e na serra do Gerês, recorrendo a repositórios bibliográficos online e à consulta presencial em bibliotecas públicas, como a Biblioteca Nacional e as Bibliotecas da Academia das Ciências, do Instituto de Conservação 
da Natureza e das Florestas e do Instituto Superior de Agronomia, a Biblioteca Pública Municipal do Porto, a Biblioteca da Faculdade de Letras da Universidade do Porto, a Biblioteca Pública de Braga e o Arquivo Distrital de Braga, a Biblioteca Geral da Universidade do Minho, e bibliotecas privadas, como a da Sociedade Martins Sarmento e a biblioteca particular do Eng.o José Neiva Vieira. Foram igualmente consultados os principais herbários portugueses, nomeadamente o do Jardim Botânico do Museu Nacional de História Natural e da Ciência (LISU), o da Universidade de Coimbra (COI) e o da Universidade do Porto (PO). Os dados do reconhecimento da população de $P$. sylvestris na serra do Gerês, obtidos em 2008/2009 (Almeida \& Fernandes 2009), foram complementados com dados registados no decurso do projeto SILVESTRE.

\section{Resultados e discussão}

\subsection{Fontes paleobotânicas}

Um dos vestígios mais antigos da presença de Pinus sylvestris na Península Ibérica é um conjunto de pinhas fossilizadas, recolhidas em depósitos turfolignitosos na região de Leiria, atribuíveis ao Pliocénico (Daveau 1894; Teixeira 1944, 1944-1945). Outros macrorrestos do Neogénico, incluindo, além de pinhas, fragmentos de madeira e de folhas de $P$. sylvestris, foram identificados em jazidas na Galiza e na Cantábria (Alcalde Olivares 2012), fornecendo informação com caráter pontual ao longo do tempo.

Uma outra fonte paleobotânica, constituída por grãos de pólen amostrados em sedimentos de turfeiras e bacias lacustres, está na base de numerosos trabalhos (ex., Franco Múgica et al. 2001; López-Merino et al. 2012; Muñoz Sobrino et al. 2007; Riera Mora 2006), permitindo obter sequências cronoestratigráficas contínuas e detetar variações bruscas na composição florística da paisagem vegetal. Porém, devido à dispersão anemófila do pólen, o conteúdo de uma turfeira pode refletir a composição vegetal de áreas muito vastas (Pais 1989) e, além disso, a identificação de pólen pode limitar-se, por vezes, à determinação da família ou do género (Seppä \& Bennett 2003), como sucede com Pinus. 
Os fragmentos de madeira semifossilizada ou semicarbonizada têm também especial interesse como fonte de informação (ex., Alcalde Olivares et al. 2003; Figueiral \& Carcaillet 2005) e, quando associados a estações arqueológicas, indiciam a ocorrência local das espécies identificadas (Figueiral 1995). Devido à dificuldade de discriminação anatómica, é por vezes adotada a designação Pinus tipo sylvestris para abranger o complexo de pinheiros orófilos ibéricos, constituído por $P$. sylvestris, $P$. nigra e $P$. uncinata (Carcaillet \& Vernet 2001; Figueiral \& Carcaillet 2005).

Alguns estudos combinam de forma integrada dados polínicos e macrorrestos fossilizados, além de informações dendrocronológicas e genéticas, permitindo efetuar reconstituições paleoambientais mais precisas (Birks \& Birks 2000; Cheddadi et al. 2006). Um desenvolvimento recente na identificação paleobotânica de $P$. sylvestris baseia-se na análise da cutícula e de estomas em fragmentos de folhas, para reconstituir detalhes da história florestal e da dinâmica da espécie (García Álvarez et al. 2009). A maioria dos estudos paleobotânicos mencionados no presente artigo circunscreve-se ao Quaternário, abordando paleoambientes vegetais com presença de $P$. sylvestris durante as glaciações plistocénicas e no Postglaciar holocénico.

\subsection{Dados paleoambientais de Pinus sylvestris na Península Ibérica e em Portugal: alguns aspetos salientes}

A distribuição atual e a diversidade morfogenética de $P$. sylvestris na Europa ocidental têm sido relacionadas com as alterações climáticas das últimas fases do Quaternário, durante as quais se registaram mudanças extremas, desde o Estadial Würmiense Final (28.000-16.000 BP) até ao Ótimo Climático Postglaciar (7000-2500 BP) (Clark et al. 2009; Lowe \& Walker 1997; Ramil Rego et al. 2009; Walker 1995). Durante as glaciações plistocénicas, regiões mediterrânicas como a Península Ibérica, a Península Itálica e os Balcãs terão constituído áreas de refúgio para espécies vegetais do norte e centro da Europa, as quais se difundiram novamente a partir dessas áreas, à medida que as condições climáticas se tornaram mais favoráveis (Cheddadi et al. 2006; Figueiral \& Terral 2002; Gómez-Orellana et al. 2012). É também admitida a existência de critpo-refúgios em latitudes mais elevadas, durante as fases glaciares, sendo detetáveis variações na dimensão das áreas de refúgio e na duração do confinamento das espécies vegetais (Stewart et al. 2010). 
Uma parte da diversidade taxonómica atual de $P$. sylvestris, constituída por um complexo de várias unidades evolutivas, pode ser atribuída à proveniência de diferentes locais de refúgio, no final da última glaciação. Como hipótese de trabalho, Sinclair et al. (1999) reconheceram pelo menos três unidades evolutivas nas populações atuais de $P$. sylvestris da Europa ocidental -na Península Ibérica, na Europa central e setentrional e no norte da Fino-Escandinávia-, resultantes de origens distintas; durante os ciclos glaciares plistocénicos, as populações ibéricas mantiveram-se isoladas no interior da área peninsular, formando uma linha evolutiva independente do processo de recolonização holocénica além-Pirenéus. A elevada diversidade de mitótipos, presente na atualidade, sugere que as populações ibéricas de $P$. sylvestris representam relíquias do Terciário, mantidas em relativo isolamento no território ibérico (Sinclair et al. 1999).

Durante o Quaternário, na formação plistocénica da praia de Maceda (Ovar), Carvalho \& Granja (2003) registaram camadas com restos de troncos atribuíveis a $P$. sylvestris, alguns em posição vertical, sugerindo a existência de uma paleofloresta desta espécie; as datações obtidas, de $20.700 \pm 300$ BP a $29.000 \pm 690$ BP, são enquadráveis no Último Máximo Glaciar, durante o qual o mar estaria muito afastado das atuais praias. Figueiral \& Carcaillet (2005) situam a presença de $P$. tipo sylvestris desde 23.900 BP em estações arqueológicas da atual região estremenha portuguesa; a abundância de vestígios antracológicos sugere a existência de uma área de refúgio em altitudes baixas, na região central de Portugal, onde a espécie permaneceu até ao Tardiglaciar (16.000-10.000 BP). Em contrapartida, são muito raros registos antracológicos em áreas setentrionais, antes do aquecimento holocénico, pois muitas estações do Paleolítico foram afetadas pela erosão costeira (Figueiral \& Carcaillet 2005). Com as alterações climáticas do início do Holocénico, os registos de $P$. sylvestris tornam-se esporádicos, refletindo o seu declínio no novo quadro fitoclimático, que favoreceu competitivamente espécies como os Querci. Adicionalmente, as transformações neolíticas do uso do solo, e a recorrência de incêndios de origem antropogénica, poderão ter contribuído para o seu declínio regional, embora alguns núcleos de $P$. sylvestris tenham sobrevivido próximo de áreas habitadas, pelo menos até há 2000 anos atrás, sendo possível que os seus últimos representantes se encontrem confinados à serra do Gerês (Figueiral \& Carcaillet 2005). 
Com efeito, a paleopalinologia admite a presença pretérita de $P$. sylvestris na serra do Gerês, desde que foram publicados os primeiros resultados de sondagens em depósitos turfosos de génese tardi a postglaciar (Bellot Rodríguez 1950). Nestes resultados inclui-se uma sondagem efetuada nos Carris, a 1450 m de altitude, na qual foi identificado pólen atribuído a $P$. sylvestris, representando 3\% do espectro polínico; segundo Bellot Rodríguez (1950), tal resultado confirmaria o caráter relicto da espécie nos pisos elevados do maciço Galaico-Duriense. Um resultado análogo foi obtido nas primeiras sondagens polínicas da serra da Estrela (Romariz 1950), numa turfeira próxima da Lagoa Comprida, a cerca de 1600 $\mathrm{m}$ de altitude, de génese postglaciar, tendo sido atribuído a $P$. sylvestris cerca de $60 \%$ do espectro polínico arbóreo.

No estado dos conhecimentos paleobotânicos em meados do século passado, admitia-se que $P$. sylvestris tivesse atingido a faixa litoral próxima da atual Leiria, e mesmo mais a sul, durante o Pliocénico e a glaciação de Würm. O aquecimento postglaciar, e as novas condições xerotérmicas, terão deslocado estes pinhais, quer para latitudes setentrionais, quer em altitude, formando maciços nalgumas montanhas Ibéricas, como as serras de Guadarrama ou do Gerês, onde, ao contrário da serra da Estrela, persistiriam até à atualidade (Gaussen 1950).

Duas análises palinológicas nas serras do Gerês e da Peneda, efetuadas por Coudé-Gaussen (1981), contribuíram para um melhor conhecimento da dinâmica regional de $P$. sylvestris. Na Lagoa do Marinho, em Couce, na serra do Gerês, a 1150 m de altitude, numa sondagem com $140 \mathrm{~cm}$ de profundidade, a espécie foi considerada presente ao longo do diagrama polínico (Fig. 1); a datação por radiocarbono de uma turfeira análoga, na serra da Peneda, aponta para uma génese recente, com cerca de 1000 anos. A desflorestação, e consequente aparição de uma paisagem arbustiva no cimo das áreas montanhosas geresianas, terá ocorrido entre 800 e 1000 d. C., em consequência de ações antropogénicas "brutais", como o sobrepastoreio e a prática de queimadas. O diagrama polínico evidencia um comportamento oposto entre as fases de predomínio de matagais e as de bosque: o aumento de espécies arbustivas, associadas a $P$. sylvestris e a Alnus glutinosa, corresponde a um recuo de espécies de Quercus, Cistus e Gramineae, e das Umbelliferae e Ranunculaceae mais termófilas. $\mathrm{O}$ aumento de $P$. sylvestris, nos níveis superiores do diagrama, refletirá as ações de arborização antropogénica empreendidas desde o final do séc. XIX. 
Uma nova sondagem na Lagoa do Marinho, efetuada por Ramil Rego et al. (1995), ampliou significativamente o período temporal analisado, obtendo-se um registo com $290 \mathrm{~cm}$ de profundidade, cujos $10 \mathrm{~cm}$ basais datam de $10.910 \pm 90 \mathrm{BP}$, correspondendo ao início da sedimentação orgânica, no final do Tardiglaciar. Nas amostras basais foi registado um predomínio de pólen arbóreo, com Pinus tipo sylvestris, Querci caducifólios e Betula, acompanhados em menor proporção por Quercus tipo ilex, Corylus e Castanea,

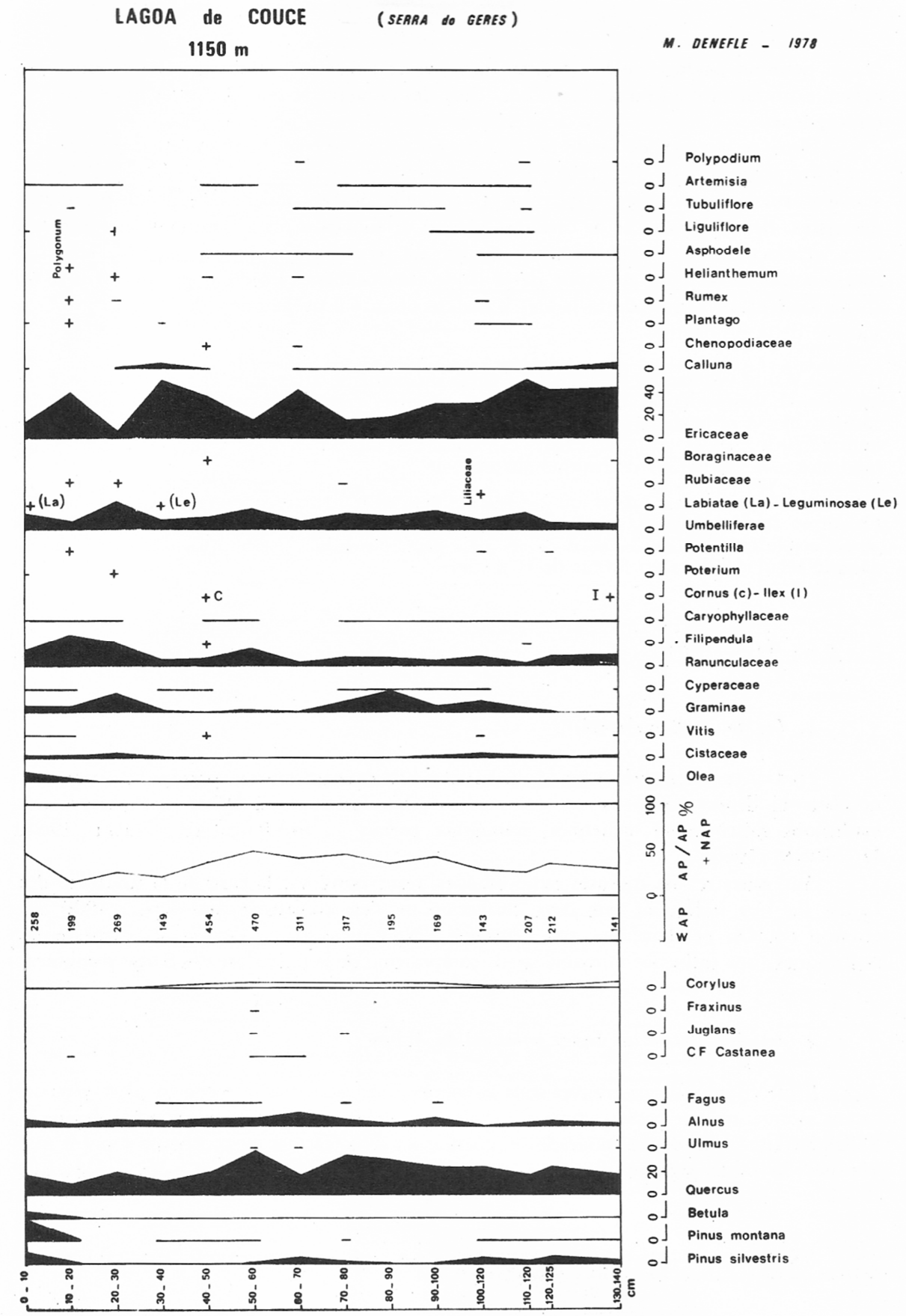

Figura 1 - Diagrama polínico da Lagoa do Marinho, em Couce, na serra do Gerês. Adaptado de Coudé-Gaussen (1981). 
sendo a fração de pólen não arbóreo dominada por Ericaceae. Este cenário polínico é concordante com o auge de uma fase de expansão das formações arbóreas, revelando condições fitoclimáticas mais benignas do que as de outros depósitos turfosos e lacustres do norte da Península Ibérica, em localizações mais interiores ou de maior altitude (Ramil Rego et al. 1995). Os dados da Lagoa do Marinho situam o auge da expansão de Querci em $7500 \pm 70 \mathrm{BP}$, marcando o início de um período de hegemonia florestal, no qual Ramil Rego et al. $(1998 ; 1995)$ admitem três unidades florestais hipotéticas:

a) formações de caráter boreal, com predomínio de Pinus cf. sylvestris e Betula cf. alba, no limite altitudinal das massas florestais;

b) formações mesófilas, a menor altitude, predominantemente caducifólias (Quercus, Alnus, Castanea, Fraxinus, Sambucus e Salix), com elementos perenifólios, como Ilex;

c) áreas marginais mais termófilas, com bosquetes de Quercus tipo ilex, Arbutus e Olea.

A aparição posterior de pólen de cereais, cerca de 5000 BP, é um indicador inequívoco da antropização da paisagem, acompanhado pela regressão das formações florestais, nomeadamente as de tipo Pinus-Betula, que se terão reduzido a indivíduos isolados, e a regressão dos bosques meso-termófilos; a progressão da antropização é testemunhada pela presença contínua de pólen de cereais, pelo incremento de Erica e pela diminuição do pólen arbóreo. A evolução mais recente da paisagem, caracterizada pelo predomínio de Erica e Calluna, e pela progressiva desaparição dos bosques, corresponde aos resultados obtidos por Coudé-Gaussen (1981), acima mencionados.

\subsection{Pinus sylvestris no Gerês: dados documentais (sécs. XVIII-XX)}

Remontam ao séc. XVIII as primeiras referências documentais à flora da serra do Gerês, resultado de memórias redigidas por eclesiásticos e das primeiras expedições de naturalistas, contemporâneas das "viagens filosóficas" empreendidas no quadro da Reforma Pombalina (Carvalho 1987). O Pe. José de Matos Ferreira, que residiu em Campo do Gerês, descreveu em 1728 os marcos miliários da via romana que atravessava a serra do Gerês, referindo elementos florísticos como "teyxos, azereyros, Pinheiros, medronheyros, Freyxos, 
Louros Regios, Platanos" (Ferreira 1982: 62); não dispomos, contudo, de qualquer elemento que permita identificar a espécie de pinheiro mencionada. Um manuscrito inédito, redigido em 1744 pelo $\mathrm{P}^{\mathrm{e}}$. Diogo Martins Pereira ${ }^{1}$, relativo à genealogia de alguns casais de São Lourenço de Cabril, Montalegre, contém informações sobre a vegetação da serra, mas não refere a ocorrência de pinheiros. Uma expedição botânica empreendida na serra do Gerês, em 1752, por Fr. Cristóvão dos Reis, farmacêutico-boticário no convento do Carmo de Braga (Reis 1779), descreve espécies vegetais características da serra, como o vidoeiro, o zimbro e o teixo, mas também não menciona a presença de pinheiros. Porém, na Memória Paroquial de Campo do Gerês, redigida em 1758 pelo abade Custódio José Leite, transcrita e editada por Capela (2001), é referida uma espécie de pinheiro que poderá corresponder a $P$. sylvestris. O questionário que serviu de base à elaboração desta memória -enviado a todos os párocos do país na sequência do terramoto de 1755-, contém um item acerca "de que plantas ou ervas medicinais a serra é povoada"; em resposta, o abade de Campo do Gerês menciona "muitas árvores silvestres com bem a ser carvalhos, cerquinhos e verinhos e alguns pinheiros que nam são dos mansos nem dos que chamamos bravos, pois criam huma folha muito miuda" (Capela 2001: 118). Embora sem outras informações, além do tamanho relativo das agulhas, esta espécie de pinheiro será, com grande probabilidade, $P$. sylvestris; a falta de um nome vernacular para a designar sugere uma ocorrência esporádica. $\mathrm{Na}$ resposta são também enumerados "teixos, medronheiros, azereiros, pradeiros, vidueiros, aveleiras e outras que parecem platanos" (Capela 2001: 118), o que sugere que o pároco memorialista possuiria, pelo menos, conhecimentos botânicos elementares.

Uma nova expedição naturalista, realizada em 1782 por Joaquim Pereira Araújo e Manuel Maia Coelho, por incumbência de D. Gaspar de Bragança, Arcebispo de Braga, permitiu efetuar "as primeiras observações de história natural da serra, com pretendido caráter científico" (Maia 1950: 628). Desta expedição resultou uma coleção mineralógica, que terá sido enviada para o Palácio de Palhavã (Lisboa 1786); mas o diário da expedição, editado por Maia (1949), refere um número muito reduzido de espécies vegetais, não sendo mencionados quaisquer pinheiros. Posteriormente, o naturalista alemão Heinrich Friedrich

\footnotetext{
${ }^{1}$ Epítome Familiar e Árvore de Geração de Algumas Casas da Freg. a de S. Lourenço de Cabril e Especialmente da Casa dos Casaes de Pinquaens (...) feito no anno de 1744 pelo Rev.o Diogo Martins Pereira [Códice dos Casais de Pincães, cópia de 1813, propriedade particular].
} 
Link passaria um mês no Gerês, em 1798, no decurso de uma viagem com o conde de Hoffmansegg, com o objetivo de reunir materiais para uma Flora de Portugal; Link menciona a ocorrência de "árvores nórdicas, que não se encontram nas planícies e nas montanhas mais baixas de Portugal" (Link 2005: 211), como o teixo, o vidoeiro, a sorveira e o zimbro, não mencionando, porém, a ocorrência de pinheiros. Já no século seguinte, um outro naturalista de origem alemã, Heinrich Moritz Willkomm, percorreria a Espanha e Portugal por diversas vezes (1844/45, 1850 e 1873), daí resultando um importante contributo para o conhecimento da flora ibérica; porém, as referências a $P$. sylvestris circunscrevem-se ao território espanhol (Devesa Alcaraz \& Viera Benítez 2001; Willkomm \& Lange 1870).

Das diversas expedições botânicas realizadas no Gerês durante o séc. XIX resultou o primeiro catálogo das plantas desta serra (Henriques 1884), que regista 345 espécies da flora vascular, incluindo duas gimnospérmicas (zimbro e teixo), mas sem qualquer espécie de pinheiro. Após a criação do Perímetro Florestal do Gerês, em 1888, no decurso do levantamento da carta florestal da serra, o silvicultor António Mendes de Almeida viria a encontrar, em 1894, exemplares de uma espécie de pinheiro distinta das vulgarmente conhecidas em Portugal, formando pequenos núcleos no setor oriental da serra, em locais elevados de difícil acesso, com árvores de idade estimada em pelo menos 100 anos; as características das pinhas, rama e carrasca levaram-no a concluir tratar-se de $P$. sylvestris, o que seria confirmado pelo botânico Pereira Coutinho (Almeida 1894, 1895; Coutinho 1913); como se referiu na Introdução, outros botânicos contemporâneos aceitaram prontamente esta descoberta. Conservam-se em LISU - Herbário do Jardim Botânico do Museu Nacional de História Natural e da Ciência dois espécimes colhidos por Mendes de Almeida (Fig. 2); a foto de um exemplar isolado, captada por este silvicultor em 1896, seria divulgada numa publicação de apologia da árvore (Sousa 1912: 175).

É plausível que estes exemplares de $P$. sylvestris tenham passado despercebidos nalgumas das expedições botânicas anteriores por estas não terem percorrido o setor oriental da serra do Gerês, devido à dificuldade de acesso e à aparente ausência de vegetação arbórea (Almeida 1894). Contudo, à data desta descoberta, que referências anteriores eram conhecidas sobre a introdução e cultivo de $P$. sylvestris em Portugal? É, porventura, na Abadia Beneditina de Tibães, próxima de Braga, que encontramos uma 

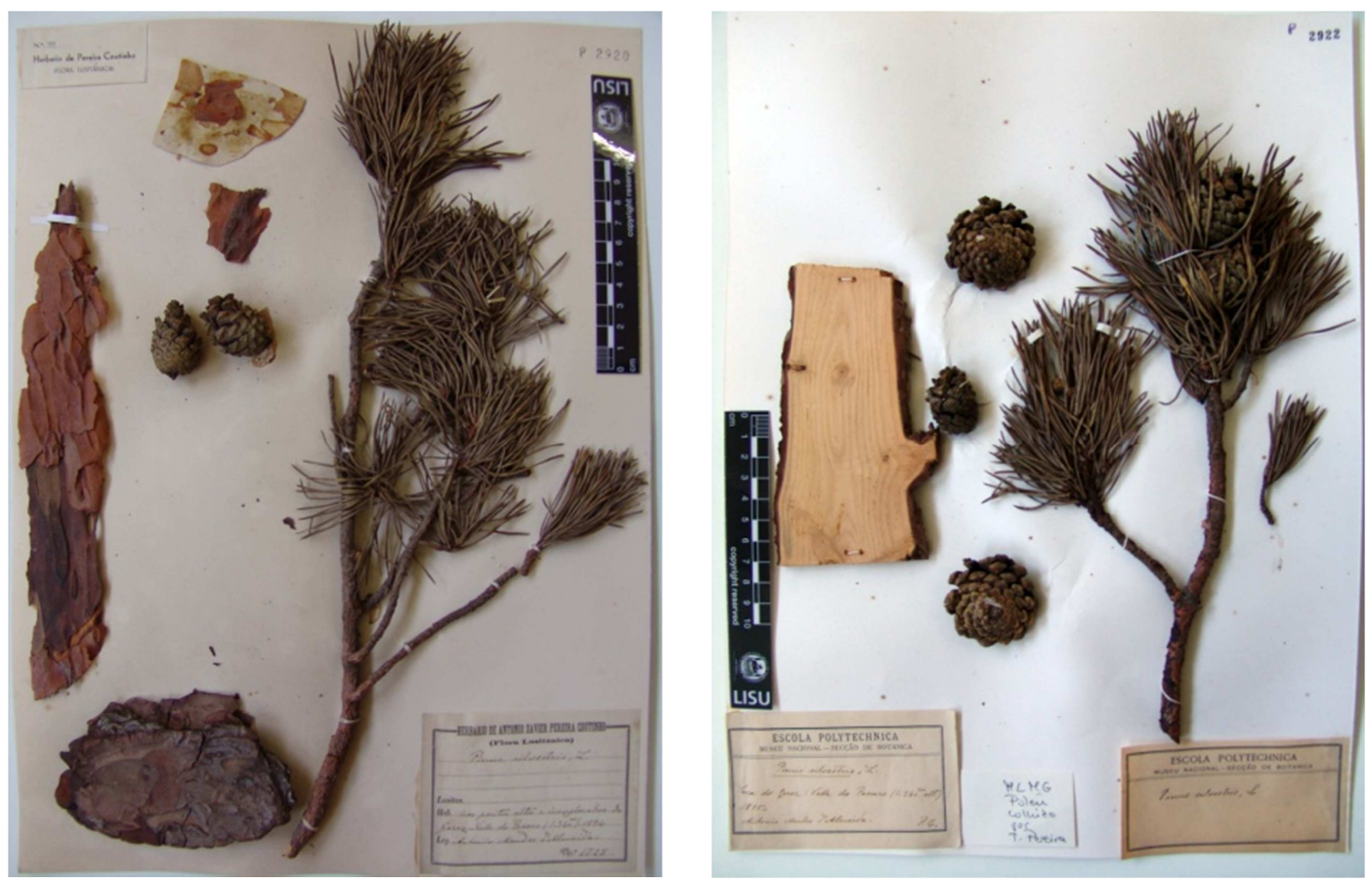

Figura 2 - Espécimes herborizados de Pinus sylvestris L. colhidos por Mendes de Almeida na serra do Gerês. Esq.: espécime colhido "nos pontos altos e inexplorados do Gerez - Valle do Passaro (1340 m)" em 1894. LISU 2920. Dir.: espécime colhido no mesmo local em 1895. LISU 2922.

(C) Ana Isabel D. Correia / Herbário LISU - Jardim Botânico - Museu Nacional de História Natural e de Ciência.

primeira informação, no quadro de atividades de fomento florestal empreendidas nos domínios monásticos, na segunda metade do séc. XVIII, com uma política ativa de plantação, proteção e reserva de áreas florestais (Oliveira 1979). Com efeito, o Estado do Mosteiro relativo ao triénio 1787-1789 menciona: "Semeou-se hum pinhal de Flandes [sic] ao redor do muro novo" ${ }^{2}$. Esta designação geográfica, com as variantes Flandes e Flandres (Bluteau 1713), é um dos qualificativos vernaculares de P. sylvestris (Colmeiro 1888; Silva 1815), aludindo à região da Europa donde a sua madeira era importada.

No séc. XIX, a Memória de J. Bonifácio de Andrada e Silva, intendente-geral das Minas e Metais do Reino, considerado o primeiro "silvicultor" português (Devy-Vareta 1989), indica a ocorrência de $P$. sylvestris em três localidades do vale do Tejo, nomeadamente na quinta dos Chavões, Cartaxo, formando uma mata "de duas legoas de comprido"; num terreno próximo de Aveiras de Cima, Azambuja, onde teria sido introduzido por iniciativa de

\footnotetext{
${ }^{2}$ Arquivo Distrital de Braga, CSB. Estados. Tibães n.o 113. Estado de 1789, fl. 13.
} 
Domingos Vandelli; e ainda a existência de outro pinhal desta espécie em Samora Correia, no concelho de Benavente (Silva 1815: 57). É também mencionada uma sementeira "em hum sitio da serra do Marão", feita em 1800, com semente "mandada vir do Norte" pelo Ministro Rodrigo de Sousa Coutinho (Silva 1815: 57). Além destes locais, o botânico Félix Brotero refere a presença de indivíduos de $P$. sylvestris no Jardim Botânico da Ajuda, então com mais de 20 anos de idade, em bom estado vegetativo (Brotero 1827). Por seu turno, o primeiro Administrador Geral das Matas, Luís Varnhagen, tendo reconhecido os locais onde havia sido introduzido anteriormente $P$. sylvestris, afirma ter encontrado apenas as duas espécies vulgares em Portugal, $P$. pinaster e $P$. pinea, referindo a ocorrência de "pinheiros exóticos" apenas em bosques de recreio e jardins botânicos (Varnhagen 1836: 69-70). Menciona ainda duas sementeiras experimentais de $P$. sylvestris efetuadas no pinhal de Leiria, em 1825 e 1826, com fracos resultados, "sendo por certo que os pinheiros do Norte não se contentão com terreno magro neste clima, e da qualidade do que neste paiz de ordinário se destina para pinhaes" (Varnhagen 1836: 72). Não obstante, existem referências posteriores à plantação de $P$. sylvestris no Buçaco $^{3}$, e ao seu cultivo em Sintra ${ }^{4}$.

Deste modo, a espécie não seria totalmente desconhecida em Portugal durante o séc. XIX, podendo levantar-se algumas dúvidas sobre a espontaneidade da população geresiana, aspeto que seria analisado pelo regente florestal Tude de Sousa, com a colaboração do botânico Gonçalo Sampaio (Sousa 1918). Apesar do exame crítico das referências anteriores, e de ter procurado indagar o estado dos espécimes introduzidos, Tude de Sousa não chegou a uma conclusão definitiva, remetendo para a eventual existência de documentos arquivados no Ministério do Fomento sobre a aquisição de semente de $P$. sylvestris em 1800, com a localização dos ensaios de plantação (Sousa 1918). Não se conhecem notícias posteriores desta documentação, apesar das diligências efetuadas por Tavares (1948), o que limita o esclarecimento da questão por esta via.

\footnotetext{
${ }^{3}$ Relatório da Administração Geral das Matas do Reino no Anno Económico de 1871-1872, Imprensa Nacional, Lisboa, 1873, p. 5.

${ }^{4}$ Catálogo da Exposição Agrícola de Lisboa em 1884, Imprensa Nacional, Lisboa, 1884, p. 577.
} 


\subsection{Pinus sylvestris e arborização da serra do Gerês}

A descoberta dos núcleos espontâneos de $P$. sylvestris na serra do Gerês, considerada de "alta importancia florestal" (Almeida 1894: 1217), motivou uma campanha de colheita de pinhas, em 1896, de que resultaram as primeiras sementeiras e plantações para propagação do "pinheiro-silvestre de Portugal" (Sousa 1919: 4). Novas campanhas de colheita, efetuadas entre 1912 e 1914, sob orientação de Tude de Sousa, deram origem a uma plantação definitiva de 13.250 exemplares no antigo viveiro da Pereira, próximo da vila do Gerês (Sousa 1918, 1926). No entanto, além da notícia inicial de Mendes de Almeida, em 1894, o que é que se conhece, em rigor, sobre os núcleos de $P$. sylvestris com possível caráter autóctone? Um reconhecimento efetuado em 1910, no setor da serra pertencente ao termo de Montalegre, indica a existência de um núcleo com cerca de 400 indivíduos, em bom estado vegetativo, com 10 a 15 m de altura, no lugar de Matança, freguesia de Cabril, de outros núcleos nos lugares de Lama Longa e Borrageirinho, da mesma freguesia, em número não determinado, e ainda núcleos em Viduíças e Lamas de Compadre, na antiga freguesia de Cela (Sousa 1918). Uma carta inédita, atribuível a Victor Branco, presidente da Câmara de Montalegre em vários mandatos desde 1898, parcialmente transcrita por Tavares (1948), refere a ocorrência de P. sylvestris na Garganta das Negras e na cabeceira do rio Cabril, próximo de Xertelo; menciona também exemplares possivelmente centenários, próximo das aldeias de Parada e Outeiro, na confluência da ribeira das Viduíças com o rio Sapinho, que teriam sido abatidos pelos seus proprietários.

Apesar do interesse inicial em propagar material vegetal dos núcleos considerados autóctones, foram realizadas arborizações em maior escala com $P$. sylvestris na mata nacional do Gerês, entre 1901 e 1914, recorrendo a sementes de origem não especificada, possivelmente importadas de França, tendo sido instaladas neste período cerca de 200.000 plantas (Sousa 1926). Especialmente importantes foram as plantações de 1903-1904 (c. 50.000 plantas) e de 1910-1911 (mais de 60.000 plantas), sendo Gramelas, Albergaria e Chã de Ranhado os locais mais intensamente arborizados (Sousa 1926). Conservam-se em PO Herbário da Faculdade de Ciências da Universidade do Porto dois espécimes herborizados 
em 1909 por Gonçalo Sampaio que atestam o cultivo de $P$. sylvestris no Gerês, proveniente quer de "sementes da serra", quer de "sementes estrangeiras"

A tendência para recorrer a material alóctone de $P$. sylvestris ter-se-á acentuado durante o Estado Novo, com a publicação da Lei do Povoamento Florestal (Lei n.o 1971, de 15 de junho de 1938), que elegeu a arborização de terrenos baldios em áreas montanhosas como um objetivo de política florestal. Com efeito, a Memória resultante do reconhecimento dos baldios a norte do Tejo, efetuado em 1935, preconiza a introdução de $P$. sylvestris em vários perímetros florestais montanhosos, nomeadamente no grupo de perímetros do Gerês (DGSFA 1940); por seu turno, o projeto de arborização do Perímetro do Gerês refere a existência de "exemplares de um pinheiro-silvestre diferente do que posteriormente foi importado para plantações", reavivando a dúvida de se tratar de "uma forma portuguesa daquela espécie" ou de, em contrapartida, "aquelas árvores constituírem derradeiros vestígios de trabalhos de arborização há muitos anos empreendidos, dos quais os últimos terão sido os de D. Maria I”6

A realização da I Reunião de Botânica Peninsular no Gerês, em 1948, suscitou a apresentação de trabalhos científicos que abordaram, à luz de novos dados, a questão da espontaneidade dos núcleos antigos de $P$. sylvestris. Além dos resultados das análises paleopalinológicas, já mencionadas, os trabalhos fitossociológicos de Rivas Goday (1950) e de Vasconcellos (1950) identificaram algumas espécies vegetais características de comunidades de P. sylvestris, como Amelanchier ovalis Medik. e Gymnadenia conopsea (L.) R. Br., consideradas como indícios a favor da espontaneidade dos núcleos remanescentes. Por seu turno, o silvicultor e botânico João do Amaral Franco, tendo efetuado o inventário da flora lenhosa exótica da serra (Franco 1950), menciona os povoamentos de $P$. sylvestris, cuja área tinha vindo a aumentar notoriamente, devido a plantações feitas quer a partir de sementes de origem autóctone, quer de sementes com outras origens; foram considerados espontâneos os núcleos de Lama Longa, Vale de Matança, Viduíças e Borrageirinho, embora não sejam mencionados os motivos para tal. Ainda no contexto desta reunião científica, o silvicultor Baeta Neves apela à proteção cuidadosa desta "relíquia preciosa" (Neves 1950:

\footnotetext{
5 Pinus sylvestris L. P0184 G.S., Gerez: Albergaria (de sementes estrangeiras), 05-1909, G. Sampaio. Idem P0185 G.S., Gerez (de sementes da serra), 17-05-1909, G. Sampaio.

${ }^{6}$ Direção Geral dos Serviços Florestais e Aquícolas, 1939, Projetos de arborização dos Perímetros do Gerês e de Terras do Bouro. Documento inédito consultado na biblioteca do Parque Nacional da Peneda Gerês.
} 
212). Assim, num momento em que se constituem algumas das bases para a futura criação do Parque Nacional da Peneda Gerês, a hipótese de a população geresiana de $P$. sylvestris ter origem autóctone é retomada com o contributo de diversas áreas de saber científico.

\subsection{Pinus sylvestris num contexto de conservação da natureza}

Após a criação do Parque Nacional da Peneda Gerês, em 1971, surgiram novas manifestações de interesse pelo estudo e salvaguarda dos núcleos remanescentes de $P$. sylvestris. Um reconhecimento efetuado por Malato-Beliz (1977) circunscreveu a área de refúgio às margens da ribeira da Viduíça e das Lamas de Compadre, considerando a população remanescente reduzida a poucas dezenas de indivíduos, apresentando o esboço cartográfico de uma área a proteger. O caráter autóctone dos núcleos remanescentes foi plenamente assumido por Silva (1979), tendo sido apresentada por Oliveira (s/ d.) uma proposta para a sua conservação genética, envolvendo a polinização artificial. Esta proposta não terá tido efeitos práticos, acabando os núcleos remanescentes por serem considerados em risco de extinção (Serra \& Carvalho 1989). Na sua tese sobre a flora e a vegetação do Parque Nacional da Peneda Gerês, Honrado (2003) admite a existência de duas populações de $P$. sylvestris provavelmente relictas, no setor oriental da Serra do Gerês; a sua sobrevivência teria sido possível devido à frugalidade e dinâmica da espécie, apta a colonizar solos relativamente pobres ou pouco evoluídos, ao carácter xerofítico e subcontinental da vertente sudeste da serra do Gerês, onde se localizam, e aos biótopos ocupados pela espécie -fundo de vales encaixados-, onde teriam sobrevivido aos incêndios que percorrem reiteradamente a serra. Um novo esboço cartográfico dos núcleos remanescentes foi publicado por Gama (2007), que efetuou o recenseamento de 1770 pinheiros, das quais considerou "antigos" apenas 181. Finalmente, Almeida \& Fernandes (2009) efetuaram um reconhecimento dos núcleos da ribeira da Dola / Biduíça e da ribeira das Negras, cujos exemplares formam uma galeria ribeirinha descontínua (Fig. 3); foram efetuados registos biométricos e colhida uma amostra xilográfica que permitiu estimar a idade de um exemplar em 220 anos, ou seja, anterior às primeiras tentativas de introdução em Portugal de material alóctone desta espécie por via oficial. 


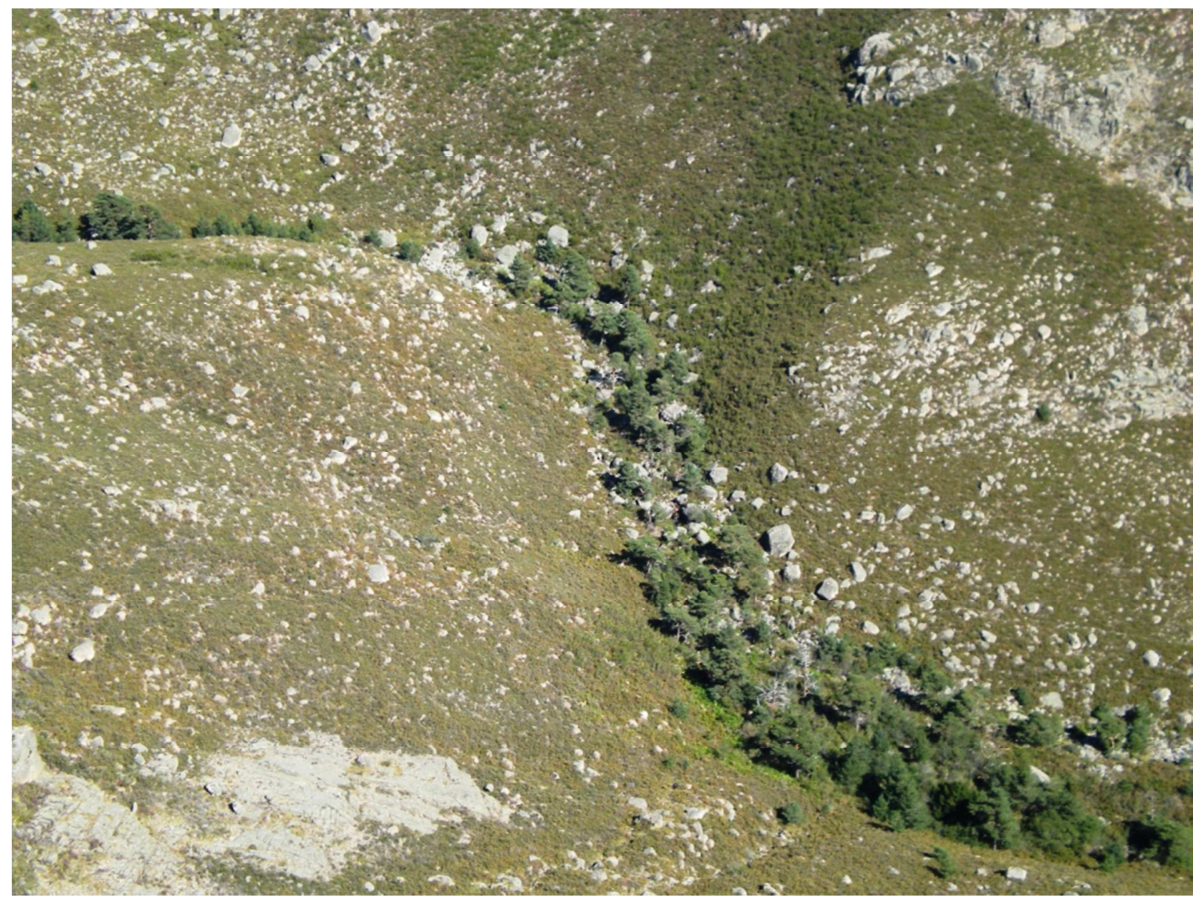

Figura 3 - Pinus sylvestris L. na ribeira das Negras, serra do Gerês. Agosto de 2009. (Foto: M. M. Fernandes)

Os dados mais recentes, relativos às características e à localização dos núcleos remanescentes de $P$. sylvestris, obtidos por Bento et al. (2014) no âmbito do projeto SILVESTRE, inventariam um total de 1563 árvores, distribuídas por 4 núcleos: ribeira da Biduíça (682 indivíduos ao longo de 2,4 km), ribeira das Negras (859 indivíduos ao longo de 2,09 km), Borrageirinho (13 indivíduos num raio de $100 \mathrm{~m}$ ) e Lama Longa (9 indivíduos num raio de 70 m). Em todos se regista abundante regeneração natural.

Refira-se, por último, que o regulamento do Plano de Ordenamento do Parque Nacional, anexo à Resolução do Conselho de Ministros n. 11-A/2011, de 4 de fevereiro, assume como um objetivo promover a preservação e restauração dos habitats de vegetação arbórea, incluindo os pinhais de pinheiro-silvestre relictos (Artigo 2.ํ, n.으)

\section{Conclusões}

No estado atual dos conhecimentos biogeográficos e paleobotânicos, pode concluir-se que os núcleos remanescentes de Pinus sylvestris da serra do Gerês são, com elevada 
probabilidade, os últimos representantes de antigas florestas desta espécie, resultantes de um historial complexo de avanços e recuos em função das condições paleoambientais do Plistocénico e do Holocénico, localizando-se atualmente no limite ocidental absoluto da área global de distribuição natural da espécie. Como se referiu, a ocorrência de populações autóctones de $P$. sylvestris na serra do Gerês remonta pelo menos ao Tardiglaciar, existindo testemunhos fósseis que documentam a presença da espécie noutras áreas do atual território continental português, desde o final do Terciário; os dados paleopalinológicos e antracológicos permitem concluir que, durante as glaciações plistocénicas, a dinâmica populacional da espécie foi afetada pela intensidade e duração dos períodos frios, pela existência de áreas de refúgio, e pelo relativo isolamento da Península Ibérica, em relação ao resto da Europa. Mencionamos a hipótese de as populações ibéricas desta espécie terem constituído linhas evolutivas independentes que, após episódios de retração e expansão, teriam sofrido uma redução drástica da sua extensão no Postglaciar holocénico, devido à alteração das condições climáticas e à possível desvantagem competitiva frente aos Querci, que se tornaram então dominantes. A fragmentação, extinção e acantonamento das populações remanescentes de $P$. sylvestris em locais montanhosos elevados, configurou 0 atual padrão de distribuição ibérica desta espécie, que se extinguiu em todo o território português, com exceção dos núcleos remanescentes na serra do Gerês. A origem autóctone destes núcleos é corroborada pelas características ecológicas dos locais onde se encontram, assim como pela informação histórica disponível. Adicionalmente, podemos mencionar a ausência de testemunhos orais sobre eventuais plantações florestais efetuadas nestes locais, contrastando com a memória local sobre outras plantações de $P$. sylvestris, efetuadas em áreas do Planalto da Mourela e em parcelas a norte de Pitões das Júnias, no concelho de Montalegre, embora mais recentes. Por outro lado, os dados citogenéticos já publicados no âmbito do projeto SILVESTRE apoiam a hipótese da origem nativa dos núcleos remanescentes (Pavia et al. 2014).

Não obstante, a "alta importância florestal" atribuída por Mendes de Almeida à descoberta dos núcleos autóctones desta espécie, no final do séc. XIX, foi sendo suplantada por uma prática de arborizações com recurso a material vegetal de origem alóctone, revelando a proeminência de um paradigma tecnocrático de florestação que marginalizou um paradigma alternativo, baseado em recursos endógenos. Desde a sua criação, o perímetro 
florestal do Gerês procurou afirmar-se como expoente político dessa visão tecnocrática para "remediar os atrasos do setor agro-florestal", no qual várias gerações de silvicultores tiveram por missão eliminar o "espectro dos incultos" através da "intervenção estatal direta nos processos da florestação"(Devy-Vareta 1989: 115).

Admitindo que o atual contexto é mais favorável à conservação da natureza, como se depreende do Plano de Ordenamento do Parque Nacional da Peneda Gerês, talvez se torne possível tomar medidas mais efetivas do que as que foram tomadas durante o último século, no sentido de conservar o património biogenético da população remanescente de $P$. sylvestris. Para que tal se concretize, nunca será demais salientar a necessidade de articular as práticas de gestão do território com uma investigação pluridisciplinar, que possibilite o cruzamento de várias disciplinas científicas e a auscultação de diferentes sensibilidades.

\section{Agradecimentos}

À Prof.a Ana Isabel D. Correia, Conservadora de Plantas Vasculares do Herbário LISU, pela cedência das imagens dos exemplares herborizados de Pinus sylvestris. Ao Prof. Francisco Barreto Caldas, da Faculdade de Ciências da Universidade do Porto, por facilitar a consulta do Herbário PO. Ao Eng.o José Neiva Vieira (ex-AFN) e ao Dr. Armando Loureiro (Parque Nacional da Peneda Gerês), pela documentação facultada. À Prof.a Rosa Fernanda Moreira da Silva, da Faculdade de Letras da Universidade do Porto, por ter facultado a consulta do manuscrito de Pincães. Ao Prof. José Viriato Capela, da Universidade do Minho, pelos seus esclarecimentos sobre as Memórias Paroquiais. Ao Prof. Aurélio de Oliveira, do ISMAI, pelas indicações documentais relativas ao mosteiro de Tibães. Ao Doutor João Pedro Tereso, do CIBIO -Centro de Investigação em Biodiversidade e Recursos Genéticos da Universidade do Porto, pela bibliografia indicada. A um referee anónimo, pelas sugestões apresentadas. Ao Eng.ํ Luís Roxo Almeida, pela sua colaboração pioneira neste trabalho.

Este trabalho foi desenvolvido no âmbito do Projeto PTDC/AGR-CFL/110988/2009 da Fundação para a Ciência e a Tecnologia (FCT) com cofinanciamento do Fundo Europeu para o Desenvolvimento Regional (FEDER), dentro do Programa COMPETE-QREN. 


\section{Bibliografia}

ALCALDE OLIVARES, C. (2012). Estudio de la macroflora en yacimientos del Neógeno y Pleistoceno inferior del noroeste peninsular: significación paleoclimática. Tesis doctoral, Escuela Técnica Superior de Ingenieros de Montes, Universidad Politécnica de Madrid.

ALCALDE OLIVARES, C., GÓMEZ MANZANEQUE, F., POSTIGO MIJARRA, J. M., SANZ, E., MENÉNDEZ-PIDAL, I. (2003). "Pinus sylvestris L. en el Pleistoceno superior del Duero (Vega Cintora, Soria, España)." Revista Cuaternario \& Geología 17 (1-2): 21-28.

ALMEIDA, A. M. (1894). "Communicação ácerca da existencia da «Pinus silvestris» na serra do Gerez." Boletim da Direç̧ão Geral de Agricultura 5 (14): 1217-1219.

ALMEIDA, A. M. (1895). "O pinheiro das nossas montanhas. Pinus sylvestris, L." Revista Florestal 2: 13-15.

ALMEIDA, L. R., FERNANDES, M. M. (2009). Pinus sylvestris L. de origem autóctone em Portugal: crónica de uma reaparição anunciada? Actas do 6. o Congresso Florestal Nacional. SPCF (Ed.). Ponta Delgada: 69-77.

BELLOT RODRÍGUEZ, F. (1950). "El análisis polínico de las zonas higroturbosas de la sierra de Gerês en relación con las presencias de Pinus pinaster Sol. in Ait. y Pinus silvestris L." Agronomia Lusitana 12 (3): 481-491.

BENITO GARZÓN, M., SÁNCHEZ DE DIOS, R., SAINZ OLLERO, H. (2008). "The evolution of the Pinus sylvestris L. area in the Iberian Peninsula from the last glacial maximum to 2100 under climate change." The Holocene 18 (5): 705-714.

BENTO, J., ROXO, L., FERNANDES, C. (2014). Os núcleos de Pinus sylvestris L. do Gerês: características e localização. Pinheiro Silvestre em Portugal: o Extremo Sudoeste ou Apenas o Fim? Considerações $e$ Desenvolvimentos no Âmbito do Projeto. J. Lima-Brito, J. Lousada and J. Bento (Eds.), UTAD, ICNF e IICT: 18-19.

BIRKS, H. H., BIRKS, H. J. B. (2000). "Future uses of pollen analysis must include plant macrofossils." Journal of Biogeography 27 (1): 31-35.

BLUTEAU, R. (1713). Flandes, ou Flandres. Vocabulario Portuguez, e Latino [...] Tomo IV. Coimbra, Collegio das Artes da Companhia de Jesu: 138-139.

BROTERO, F. A. (1827). Historia natural dos pinheiros, lárices e abetos. Lisboa, Impressão Régia, 152 p.

CAPELA, J. V. (Ed.) (2001). Memórias e Imagens de Terras do Bouro Antigo. As Memórias Paroquiais de 1758. Terras de Bouro, Câmara Municipal de Terras de Bouro, 221 p.

CARCAILleT, C., VERNET, J.-L. (2001). "Comments on "The Full-Glacial Forests of Central and Southeastern Europe" by Willis et al." Quaternary Research 55 (3): 385-387.

CARVALHO, G. S., GRANJA, H. M. (2003). "As mudanças da zona costeira pela interpretação dos sedimentos plistocénicos e holocénicos (a metodologia aplicada na zona costeira do NO de Portugal)." Revista da Faculdade de Letras - Geografia 19: 225-236.

CARVALHO, R. (1987). A História Natural em Portugal no Século XVIII. Lisboa, Instituto de Cultura e Língua Portuguesa, $123 \mathrm{p}$.

CHEDDADI, R., VENDRAMIN, G. G., LITT, T., FRANÇOIS, L., KAGEYAMA, M., LORENTZ, S., LAURENT, J.-M., DE BEAULIEU, J.-L., SADORI, L., JOST, A., LUNT, D. (2006). "Imprints of glacial refugia in the modern genetic diversity of Pinus sylvestris." Global Ecology and Biogeography 15 (3): 271-282.

CLARK, P. U., DYKE, A. S., SHAKUN, J. D., CARLSON, A. E., CLARK, J., WOHLFARTH, B., MITROVICA, J. X., HOSTETLER, S. W., MCCABE, A. M. (2009). "The Last Glacial Maximum." Science 325 (5941): 710-714.

COLMEIRO, M. (1888). Pinus sylvestris L. Enumeración y revisión de las plantas de la Península HispanoLusitana é islas Baleares [...] Tomo IV. Madrid, Imprenta de la Viuda é Hija de Fuentenebro: 710-712.

COUdÉ-GAUSSEN, G. (1981). Les Serras da Peneda et du Gerês (Minho, Portugal). Étude Géomorphologique. Lisboa, Centro de Estudos Geográficos, 255 p. 
COUTINHO, A. X. P. (1913). A Flora de Portugal (Plantas vasculares) Disposta em Chaves Dichotomicas. Lisboa, Aillaud, Alves \& Cia., 766 p.

CRITCHFIELD, W. B., LITTLE, E. L. (1966). Geographic Distribution of the Pines of the World. Washigton, D. C., U.S. Department of Agriculture, Forest Service, $97 \mathrm{p}$.

DAVEAU, M. J. (1894). "Sur l'aire d'extension du pin sylvestre dans la Péninsule Ibérique." Journal de Botanique 8: 401-403.

DEVESA ALCARAZ, J. A., VIERA BENÍTEZ, M. C. (2001). Viajes de un botánico sajón por la Península Ibérica (H. M. Willkomm, 1821-1895). Cáceres, Servicio de Publicaciones, Universidad de Extremadura, 375 p.

DEVY-VARETA, N. (1989). "Os Serviços Florestais no século XIX. Os homens e as ideias." Finisterra - Revista Portuguesa de Geografia 24 (47): 105-116.

DGSFA (1940). Memória sôbre o reconhecimento dos baldios no norte do Tejo efetuado em 1935. Plano de Povoamento Florestal. MA (Ed.). Lisboa, Imprensa Nacional: 34-137.

FERREIRA, J. M. (1982). Thesouro de Braga Descuberto no Campo do Gerez [1728]. Braga, Câmara Municipal de Terras do Bouro, $93 \mathrm{p}$.

FIGUEIRAL, I. (1995). "Charcoal analysis and the history of Pinus pinaster (cluster pine) in Portugal." Review of Palaeobotany and Palynology 89: 441-454.

FIGUEIRAL, I., CARCAILLET, C. (2005). "A review of Late Pleistocene and Holocene biogeography of highland Mediterranean pines (Pinus type sylvestris) in Portugal, based on wood charcoal." Quaternary Science Reviews 24 (23-24): 2466-2476.

FIGUEIRAL, I., TERRAL, J. F. (2002). "Late Quaternary refugia of Mediterranean taxa in the Portuguese Estremadura: charcoal based palaeovegetation and climatic reconstruction." Quaternary Science Reviews 21 (4-6): 549-558.

FRANCO, J. A. (1950). "Flora exótica da serra do Gerês." Agronomia Lusitana 12 (2): 381-402.

FRANCO, J. A. (1986). Pinus L. Flora Iberica. Plantas vasculares de la Península Ibérica e Islas Baleares. S. Castroviejo (Ed.). Madrid, Real Jardín Botánico, C.S.I.C.: 168-174.

FRANCO MÚGICA, F., GARCíA ANTÓN, M., MALDONADO RUIZ, J., MORLA JUARISTI, C., SAINZ OLLERO, H. (2001). "The Holocene history of Pinus forests in the Spanish Northern Meseta." The Holocene 11 (3): 343-358.

GAMA, M. D. (2007). O pinheiro-silvestre primitivo da serra do Gerês. Porto, FAPAS - Fundo para a Proteção dos Animais Selvagens, $43 \mathrm{p}$.

GARCíA-AMORENA, I., GÓMEZ MANZANEQUE, F., RUBIALES, J. M., GRANJA, H. M., SOARES DE CARVALHO, G., MORLA, C. (2007). "The Late Quaternary coastal forests of western Iberia: A study of their macroremains." Palaeogeography, Palaeoclimatology, Palaeoecology 254 (3-4): 448-461.

GARCÍA ÁlVAREZ, S., MORLA JUARISTI, C., SOlANA GUTIÉRREZ, J., GARCÍA-AMORENA, I. (2009). "Taxonomic differences between Pinus sylvestris and $P$. uncinata revealed in the stomata and cuticle characters for use in the study of fossil material." Review of Palaeobotany and Palynology 155 (1-2): 61-68.

GAUSSEN, H. (1950). L'influence du passé dans la répartition des Gymnospermes de la Péninsule Ibérique. Comptes Rendus du Congres International de Geographie. Lisbonne 1949. Tome II, Travaux des Sections II et III. Lisbonne [Lisboa], Union Géographique Internationale: 805-821.

GÓMEZ-ORELLANA, L., RAMIL REGO, P., MUÑOZ SOBRINO, C. (2012). Refúgios para árvores temperadas caducifólias an área litoral do noroeste ibérico durante o último período glaciar. Environmental Changes and Human Interaction Along the Western Atlantic Edge. A. Campar Almeida, A. M. S. Bettencourt, D. M. S. Monteiro-Rodrigues and M. I. C. Alves (Eds.). Coimbra, APEQ, CITCEM, CEGOT, CGUP, CCT: 95-106.

HENRIQUES, J. A. (1884). "A vegetação da serra do Gerez." Boletim da Sociedade Broteriana 3 (3): 155-225.

HENRIQUES, J. A. (1896). "Contribuição para a flora de Portugal." Boletim da Sociedade Broteriana 13: 60-70.

HONRADO, J. J. P. (2003). Flora e Vegetação do Parque Nacional da Peneda-Gerês. Dissertação de candidatura ao grau de Doutor em Biologia, Faculdade de Ciências da Universidade do Porto. 
LIMA-BRITO, J., LOUSADA, J., BENTO, J. (Eds.). (2014). Pinheiro Silvestre em Portugal: O Extremo Sudoeste ou Apenas o Fim? Considerações e Desenvolvimentos no Âmbito do Projeto. UTAD, ICNF, IICT, 46 p.

LINK, H. F. (2005). Notas de uma viagem a Portugal e através de França e Espanha. Lisboa, Biblioteca Nacional, $304 \mathrm{p}$.

LISBOA, B. S. (1786). Discurso Histórico, Político e Económico dos Progressos, e Estado Actual da Filosofia Natural Portuguesa [...]. Lisboa, Off. António Gomes, 68 p.

LÓPEZ-MERINO, L., SILVA SÁNCHEZ, N., KAAL, J., LÓPEZ-SÁEZ, J. A., MARTíNEZ CORTIZAS, A. (2012). "Postdisturbance vegetation dynamics during the Late Pleistocene and the Holocene: An example from NW Iberia." Global and Planetary Change 92-93 (0): 58-70.

LOWE, J. J., WALKER, J. C. (1997). Reconstructing Quaternary Environments. Oxon, 2nd ed., Routledge, 472 p.

MAIA, C. (Ed.) (1949). Diário Filosófico da Viagem ao Gerês de Joaquim Vicente Pereira Araújo. Porto, Livraria Figueirinhas, $57 \mathrm{p}$.

MAIA, C. (1950). "As primeiras observações botânicas feitas no Gerês." Agronomia Lusitana 12 (4): 627-632.

MALATO-BELIZ, J. (1977). Noroeste. Interesse da Proteç̧ão da Flora e da Vegetação Nalgumas Zonas. Relatório inédito, [Gabinete do Plano da Região do Porto].

MARTÍNEZ GARCÍA, F. (1999). Los bosques de Pinus sylvestris L. del Sistema Central español : distribución, historia, composición florística y tipología. Tesis doctoral, Facultad de Ciencias Biológicas, Universidad Complutense de Madrid.

MARTÍNEZ GARCÍA, F., MONTERO, G. (2000). "Typology of Pinus sylvestris L. forests in Spain." Investigación Agraria Sistemas y Recursos Forestales Fuera de Serie n.o 1: 41-65.

MUÑOZ SOBRINO, C., RAMIL-REGO, P., GÓMEZ-ORELLANA, L. (2007). "Late Würm and early Holocene in the mountains of northwest Iberia: biostratigraphy, chronology and tree colonization." Vegetation History and Archaeobotany 16: 223-240.

NEVES, C. B. (1950). "O "Pinheiro silvestre" na Serra do Gerez." Gazeta das Aldeias 2179: 211-213.

OLIVEIRA, A. A. (1979). A Abadia de Tibães 1630/80-1813. Propriedade, exploração e produção agrícolas no vale do Cávado durante o Antigo Regime. Dissertação para Doutoramento em História Moderna e Contemporânea, Faculdade de Letras da Universidade do Porto.

OLIVEIRA, J. A. L. (s/ d.). Observações referentes à Pinus silvestris no Parque Nacional da Peneda Gerês. Relatório interno, [Parque Nacional da Peneda Gerês].

PAIS, J. (1989). "Evolução da cobertura florestal em Portugal no Neogénico e no Quaternário." Comunicações dos Serviços Geológicos de Portugal 75: 67-72.

PAVIA, I., MENGL, M., GASPAR, M. J., CARVALHO, A., HEINZE, B., LIMA-BRITO, J. (2014). "Preliminary evidences of two potential native populations of Pinus sylvestris L. in Portugal based on nuclear and chloroplast SSR markers." Austrian Journal of Forest Science 131 (1): 1-22.

PRUS-GŁOWACKI, W., STEPHAN, B. R., BUJAS, E., ALIA, R., MARCINIAK, A. (2003). "Genetic differentiation of autochthonous populations of Pinus sylvestris (Pinaceae) from the Iberian peninsula." Plant Systematics and Evolution 239 (1-2): 55-66.

RAMIL-REGO, P., MUÑOZ-SOBRINO, C., RODRÍGUEZ-GUITIÁN, M., GÓMEZ-ORELLANA, L. (1998). "Differences in the vegetation of the North Iberian Peninsula during the last 16,000 years." Plant Ecology 138: 41-62.

RAMIL REGO, P., AIRA RODRÍGUEZ, M. J., ALONSO MATTIAS, F. (1995). Caracterización climática y vegetacional de la serra de Gerês (Portugal) durante el Tardiglaciar y el Holoceno: análisis polínico de a Lagoa do Marinho. Actas da 3. a Reunião do Quaternário Ibérico. Coimbra, 27 de Setembro a 1 de Outubro de 1993. M. Mateus (Ed.). Coimbra, Universidade de Coimbra: 85-92.

RAMIL REGO, P., GÓMEZ-ORELLANA, L., MUÑOZ-SOBRINO, C., GARCÍA-GIL, S., IGLESIAS, J., PÉREZ MARTÍNEZ, M., MARTÍNEZ CARREÑO, N., NÓVOA FERNÁNDEZ, B. (2009). "Cambio climático y dinámica del paisaje en Galicia." Recursos Rurais 5: 21-47. 
REIS, C. (1779). Reflexões experimentaes methodico-botanicas, muito uteis, e necessarias para os professores de medicina, e enfermos. Lisboa, Regia Officina Typografica, 352 p.

RIERA MORA, S. (2006). "Cambios vegetales holocenos en la región mediterránea de la Península Ibérica: ensayo de síntesis." Ecosistemas 15 (1): 17-30.

RIVAS GODAY, S. (1950). "Apreciación sintética de los grados de vegetación de la Sierra de Gerês." Agronomia Lusitana 12 (3): 449-480.

ROMARIZ, C. (1950). Contribuição da análise polínica no estudo da vegetação primitiva da Serra da Estrela. Comptes Rendus do Congrès Internacional de Géographie. Lisbonne 1949. Tome II, Travaux des Sections II et III. Lisbonne [Lisboa], Union Géographique Internationale: 824-830.

SEPPÄ, H., BENNETT, K. D. (2003). "Quaternary pollen analysis: recent progress in palaeoecology and palaeoclimatology." Progress in Physical Geography 27 (4): 548-579.

SERRA, M. G. L., CARVALHO, M. L. S. (1989). A Flora e a Vegetação do Parque Nacional da Peneda-Gerês. Contribuição para o Plano de Ordenamento desta Área Protegida. Lisboa, Serviço Nacional de Parques, Reservas e Conservação da Natureza, 78 p.

SILVA, A. R. P. (1979). "Plantas em perigo. Pinheiro-silvestre. Pinus sylvestris L." Boletim da Comissão Nacional do Ambiente 5 (1 - Anexo): 1-2.

SILVA, J. B. A. (1815). Memoria sobre a necessidade e utilidades do plantio de novos bosques em Portugal, particularmente de pinhaes nos areaes de beira-mar; seu methodo de sementeira, costeamento $e$ administração. Lisboa, Academia Real das Sciencias, 187 p.

SINCLAIR, W. T., MORMAN, J. D., ENNOS, R. A. (1999). "The postglacial history of Scots pine (Pinus sylvestris L.) in western Europe: evidence from mitochondrial DNA variation." Molecular Ecology 8 (1): 83-88.

SOUSA, T. M. (1912). A Árvore. Leituras Florestais para Crianças / Notas para Criar, Desenvolver e Fomentar o Amor pelas Árvores e pela Montanha. Porto, Livraria Chardron, $200 \mathrm{p}$.

SOUSA, T. M. (1918). "O pinheiro silvestre de Portugal. Problema de arqueologia e investigação apresentado à Conferência Florestal." Boletim da Secretaria de Estado da Agricultura 1: 65-71.

SOUSA, T. M. (1919). Conferência Florestal de 1916. Excursões dos conferentes. Lisboa, Separata da Voz d'O Lavrador, La Bécarre, 8 p.

SOUSA, T. M. (1926). Mata do Gerês. Subsídios para uma Monografia Florestal. Coimbra, Separata d'A Voz do Lavrador, Imprensa da Universidade, 253 p.

STEWART, J. R., LISTER, A. M., BARNES, I., DALÉN, L. (2010). "Refugia revisited: individualistic responses of species in space and time." Proceedings of the Royal Society B: Biological Sciences 277 (1682): 661-671.

TAVARES, H. M. (1948). Contribuição para o Estudo da "Pinus silvestris, L." (Serras do Gerez e Cabreira). Relatório final de curso de Engenheiro Silvicultor, Universidade Técnica de Lisboa, Instituto Superior de Agronomia.

TEIXEIRA, C. (1944). "A expansão do Pinus sy/vestris L. no Sudoeste da Europa e a mudança climática dos fins do Pliocénico." Anais da Faculdade de Ciências do Porto 29: 21-26.

TEIXEIRA, C. (1944-1945). "Subsídios para a história evolutiva do pinheiro dentro da flora portuguesa." Boletim da Sociedade Broteriana 19 (2.a série): 209-221.

VARNHAGEN, F. L. G. (1836). Manual de instrucções praticas sobre a sementeira, cultura e corte dos pinheiros, e conservação da madeira dos mesmos; indicando-se os methodos mais proprios para o clima de Portugal. Lisboa, Typografia da Academia, $101 \mathrm{p}$.

VASCONCELLOS, J. C. (1950). "Proteção à flora do Gerês." Agronomia Lusitana 12 (4): 611-617.

WALKER, M. J. C. (1995). "Climatic changes in Europe during the last glacial/interglacial transition." Quaternary International 28: 63-76.

WILLKOMM, M., LANGE, J. (1870). Prodromus florae hispanicae seu synopsis methodica omnium plantarum in Hispania sponte nascentium vel frequentius cultarum quae innoterunt. Volumen I. Sttutgartia [Sttutgart], Sumtibus E. Schweizerbart, 316 p. 